\title{
Fungsi Menu-Menu Microsoft Word 2013
}

\author{
Khoirul Ngibad $^{1}$ \\ ${ }^{1}$ Universitas Maarif Hasyim Latif Sidoarjo \\ khoirul_ngibad@dosen.umaha.ac.id
}

\begin{abstract}
Abstrak
Aplikasi software Microsoft Office Word sangat berguna di kalangan akademik dan perkantoran. Dengan semakin majunya teknologi komputer, software Microsoft Office Word juga semakin canggih dan sampai saat ini sudah diluncurkan Microsoft Office Word 2013. Artikel ini merupakan hasil kajian pustaka mengenai fungsi tab menu Microsoft Office Word 2013 yang sudah dipraktikkan. Melalui artikel ini, diharapkan dapat bisa dijadikan panduan dan acuan baik di kalangan akademik maupun perkantoran.
\end{abstract}

Kata Kunci : Aplikasi komputer, ms. office word 2013, fungsi tab menu

\section{Pendahuluan}

Pada zaman dahulu, manusia masih menggunakan mesin ketik untuk keperluan tulis menulis tetapi pada zaman sekarang manusia sudah menggunakan teknologi yang maju, seperti komputer. Peranan komputer dalam berbagai bidang kehidupan semakin dirasakan manfaatnya mulai dari kalangan akademik sampai masyarakat awam sekalipun. Penggunaan software komputer, seperti software Microsoft Office Word sangat berguna dalam aplikasi perkantoran. Salah satu contohnya adalah penggunaan ikon copy pada menu Home dalam software Microsoft Office Word yang berfungsi untuk menggandakan tulisan, gambar, folder, software aplikasi dan lain sebagainya. Dengan memakai fungsi ikon copy tersebut, maka pekerjaan akan semakin mudah, cepat dan efisien.

Aplikasi software Microsoft Office Word banyak digunakan di kalangan akademik dan perkantoran. Mulai dari Sekolah Dasar sampai Perguran Tinggi sudah diperkenalkan, diajarkan, dan dipraktikkan mengenai penggunan aplikasi software Microsoft Office Word. Mata kuliah aplikasi komputer yang diajarkan di Perguruan Tinggi bertujuan agar mahasiswa mempunyai kemampuan dalam mengoperasikan software Microsoft Office Word yang akan digunakan untuk menyeselesaikan tugas - tugas kuliah seperti makalah, laporan PKL, karya tulis ilmiah, artikel ilmiah dan lain-lain. Dengan demikian, di era digital seperti ini menuntut para mahasiswa untuk mampu menguasai penggunaan Aplikasi software Microsoft Office Word agar perkuliahannya berjalan dengan lancar.

Di sisi lain, aplikasi software Microsoft Office Word tersebut selalu mengalami perkembangan mulai dari Microsoft Office 2000, Microsoft Office XP (2002), Microsoft Office 2003, Microsoft Office 2007, Microsoft Office 2010, dan Microsoft Office 2013. Semakin update, aplikasi Ms. Office Word ini semakin bagus karena dilengkapi dengan fitur - fitur terbaru yang akan semakin mempermudah dalam menyelasaikan tugas - tugas baik di kalangan akademik maupun perkantoran. Selain itu, ternyata ada beberapa perbedaan antara Microsoft Office versi lama dan terbaru, misalnya dari tampilan tab menu. Oleh karena itu, dalam artikel 
ini, akan diperkenalkan dan dibahas fungsi tab menu pada Microsoft Office agar bisa dijadikan panduan dan acuan baik di kalangan akademik maupun di perkantoran.

\section{Macam-Macam Microsoft Office 2013}

Microsoft Office merupakan software atau perangkat lunak yang dibuat oleh Microsoft Coorporation yang dijalankan di bawah sistem operasi Windows yang berfungsi untuk memudahkan tugas perkantoran. Dengan menggunakan software Microsoft Office, seseorang dapat mengetik berbagai jenis proposal, karya ilmiah, surat, invoice, laporan kinerja karyawan, laporan keuangan, database karyawan, presentasi, membuat gambar dalam bentuk JPEG, dan lain-lain. Hingga tahun 2000-an, Microsoft Coorporation telah meluncurkan berbagai versi Microsoft Office antara lain: Microsoft Office 2000, Microsoft Office XP (2002), Microsoft Office 2003, Microsoft Office 2007, Microsoft Office 2010, dan Microsoft Office 2013.

Artikel ini akan memfokuskan pembahasan pada Microsoft Office 2013. Beberapa program dari Microsoft Office 2013 (Gambar 1) antara lain :

1. $\quad$ Word 2013

2. Powerpoint 2013

3. Excel 2013

4. Acess 2013

5. Database compare 2013

7. Lync 2013

8. Lync recording manager

9. Office 2013 language preferences

10. Office 2013 upload center
11. Onenote 2013

12. Outlook 2013

13. Publisher 2013

14. Send to onenote 2013

15. Skydrive pro 2013

16. Spreadsheet compare 2013

17. Telemetry dashboard for office

18. Telemetry log for office 2013 
A를 Access 2013

जबञ Database Compare 2013

X青 Excel 2013

I 〔 InfoPath Designer 2013

I † InfoPath Filler 2013

L $\$$ Lync 2013

L 8 Lync Recording Manager

A Office 2013 Language Preferences

(1) Office 2013 Upload Center

NE OneNote 2013

OY Outlook 2013

P 5 PowerPoint 2013

P 기 Publisher 2013

NE. Send to OneNote 2013

6 SkyDrive Pro 2013

Bif톨 Spreadsheet Compare 2013

EI Telemetry Dashboard for Office...

EQ Telemetry Log for Office 2013

W无 Word 2013

(116) Microsoft Solitaire Collection

iㅛ Microsoft Store

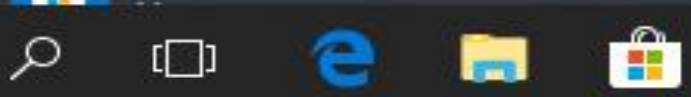

Gambar 1. Hasil screenshot tampilan beberapa software Microsoft 2013 
Beberapa fungsi beberapa program dari Microsoft Office 2013 yang sering digunakan untuk perkantoran antara lain :

1. $\quad$ Word 2013

Berfungsi untuk mengolah kata dari Microsoft (komposisi, mengedit, memformat, dan mencetak hasil) (Hasyim, 2009). Tampilan utama Microsoft Office Word 2013 disajikan dalam Gambar 2.

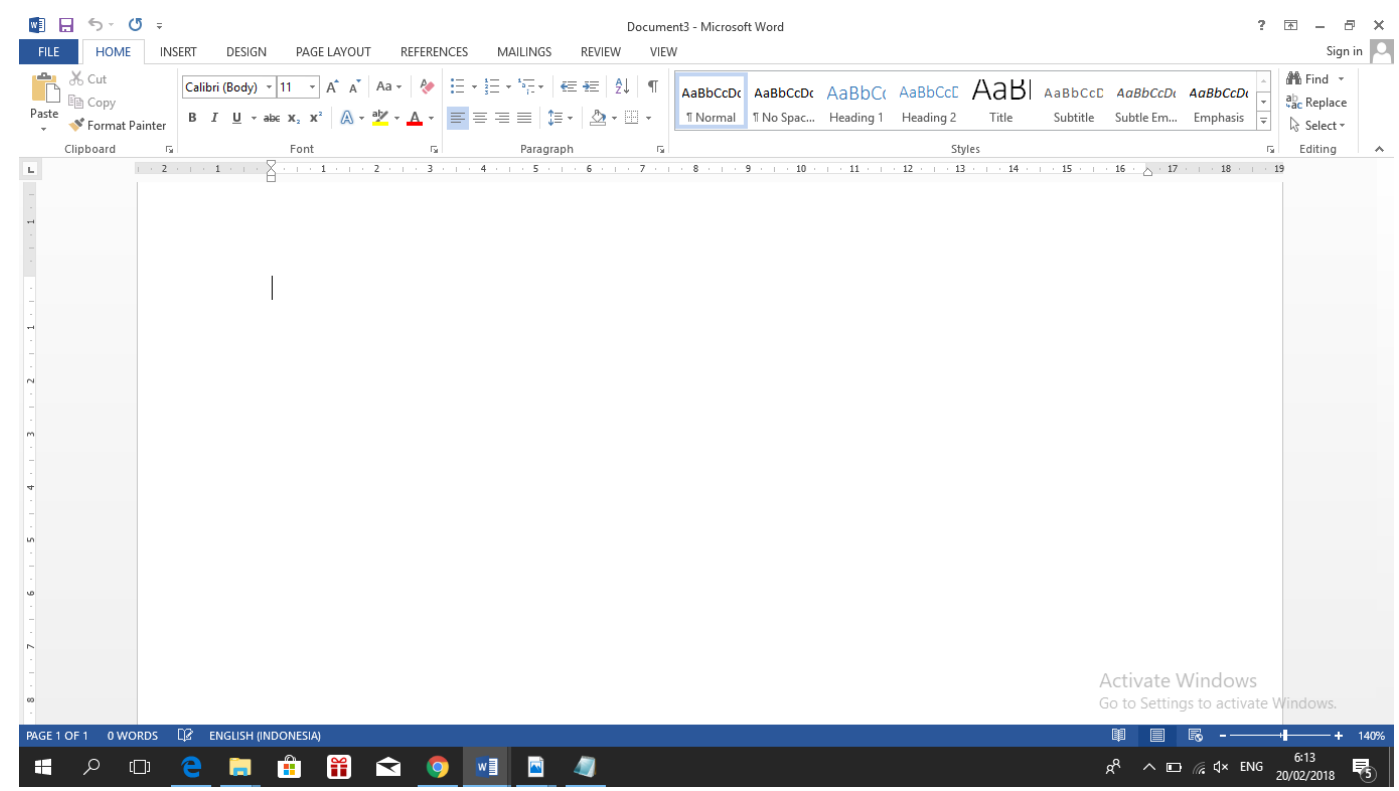

Gambar 2. Hasil screenshot tampilan Ms. Word 2013

2. Powerpoint 2013

Berfungi untuk membuat slide-slide yang dapat membantu dalam proses, mengajar, dan membuat animasi sederhana (Adi, 2017). Tampilan utama Microsoft Office PowerPoint 2013 disajikan dalam Gambar 3.

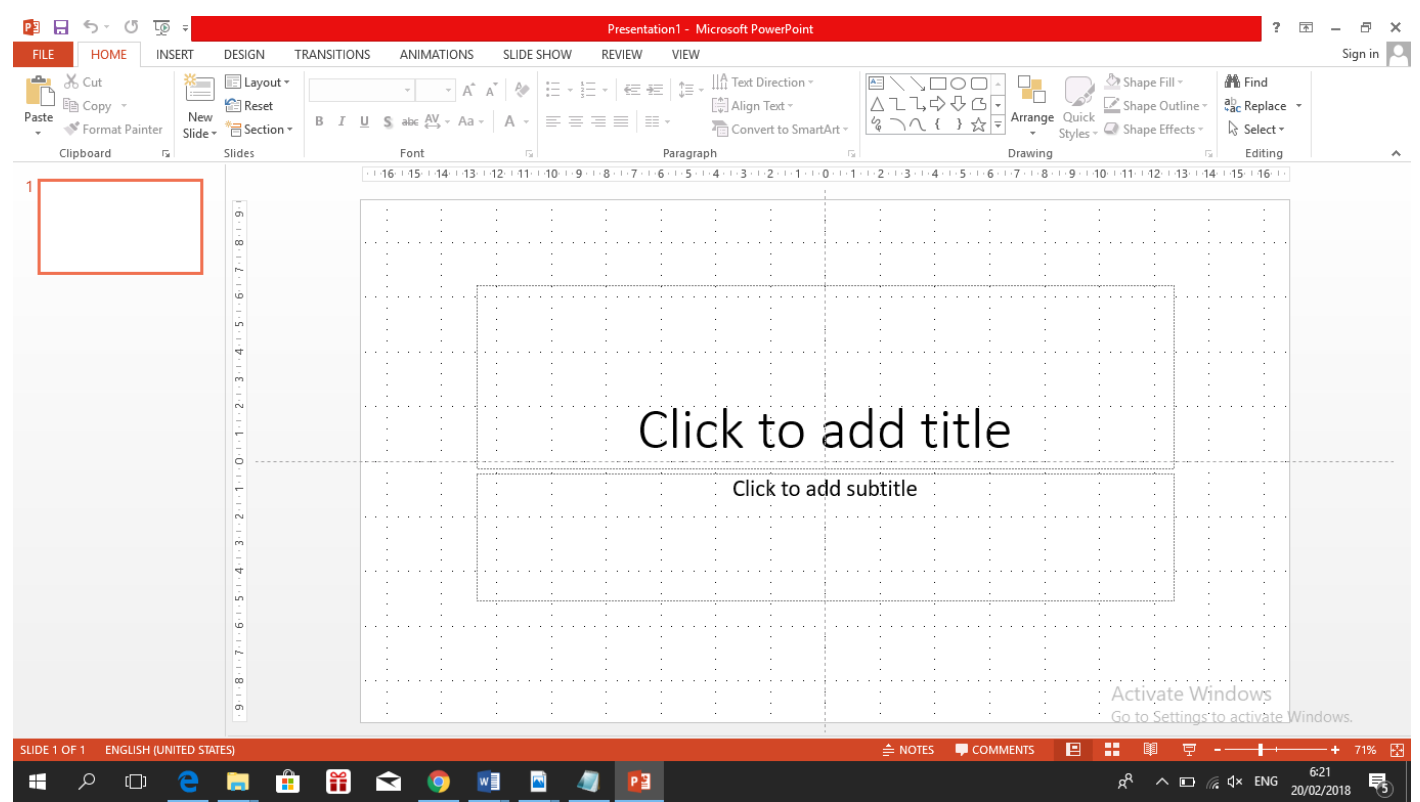

Gambar 3. Hasil screenshot tampilan Ms. Powerpoint 2013 
3. Excel 2013

Berfungi untuk pengolahan data yang berupa angka (Hatoko, 2016). Tampilan utama Microsoft Office Excel 2013 disajikan dalam Gambar 4.

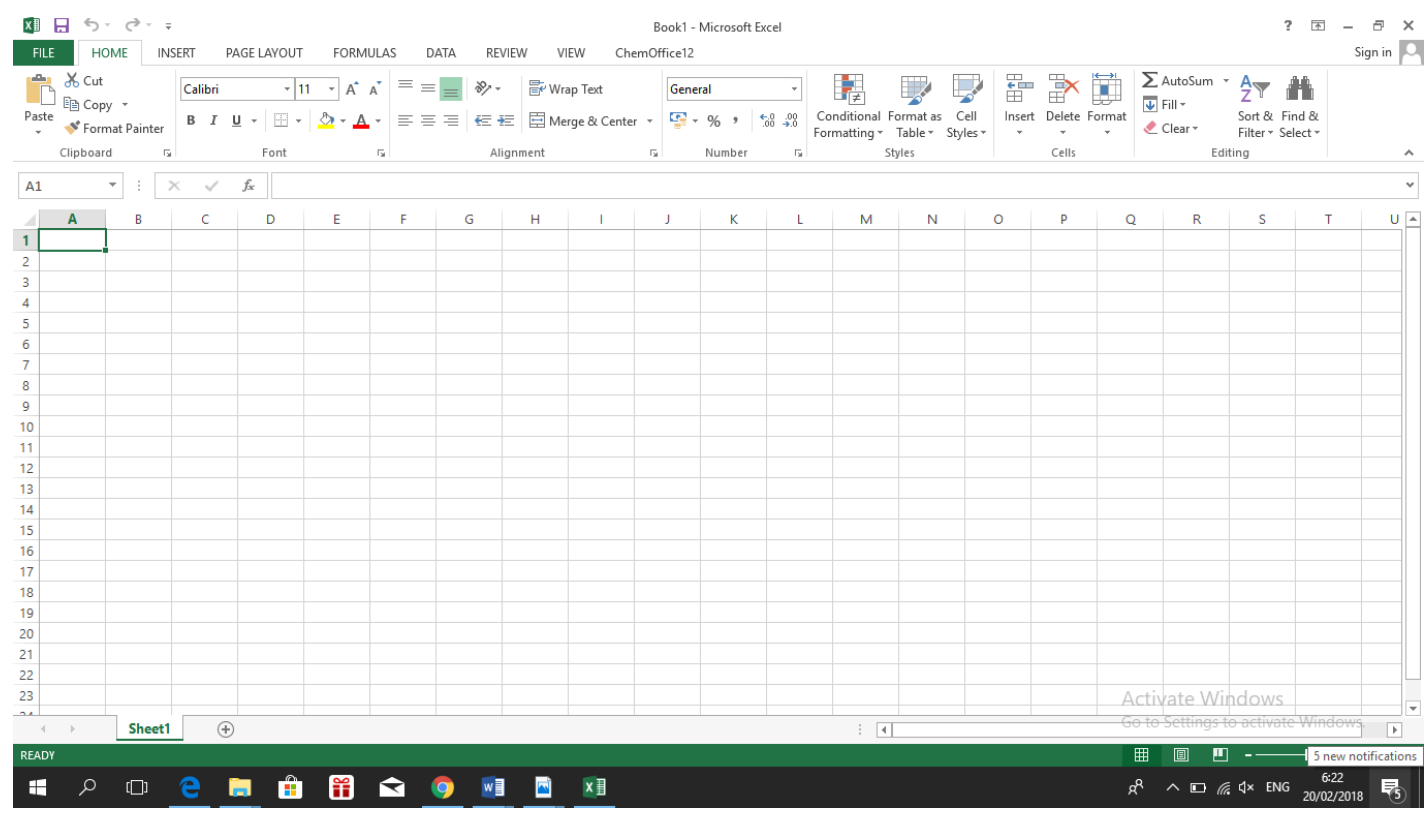

Gambar 4. Hasil screenshot tampilan Ms. excel 2013

\section{Fungsi Menu-Menu pada Tab Home Microsoft Word 2013}

\subsection{Home}

Salah satu menu Tab pada Microsoft Word 2013 adalah HOME. Menu HOME ini terdiri dari beberapa kelompok sub tema antara lain (Gambar 5):

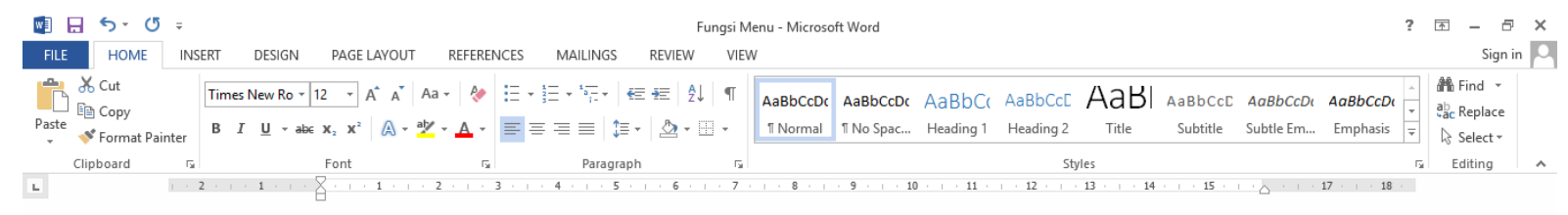

Gambar 5. Hasil screenshot tampilan dan kelompok tab menu Home

\section{Kelompok Clipboard}

Secara umum berfungi untuk menggandakan, memindahkan dan memposisikan/meletakkan tulisan/objek gambar.

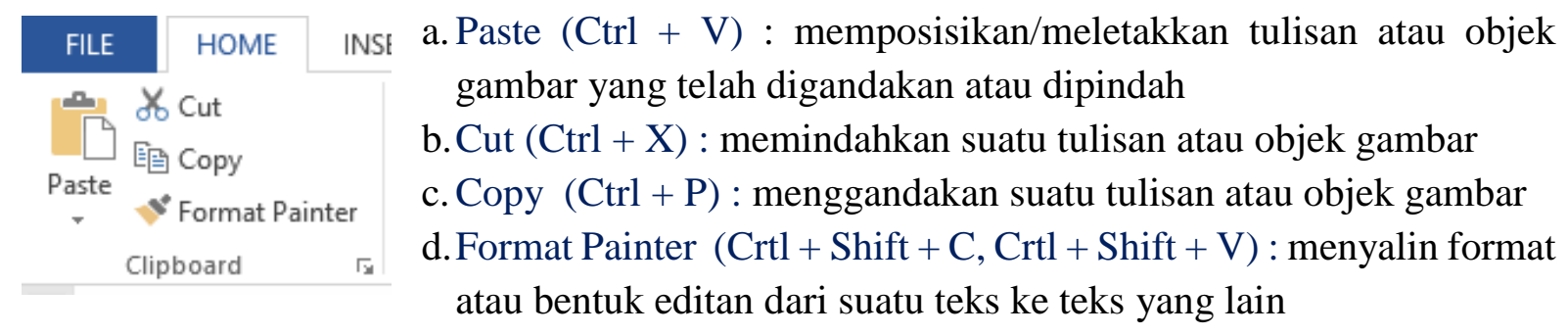




\section{Kelompok Font}

Secara umum berfungsi untuk mengatur jenis, ukuran, warna gaya tulisan

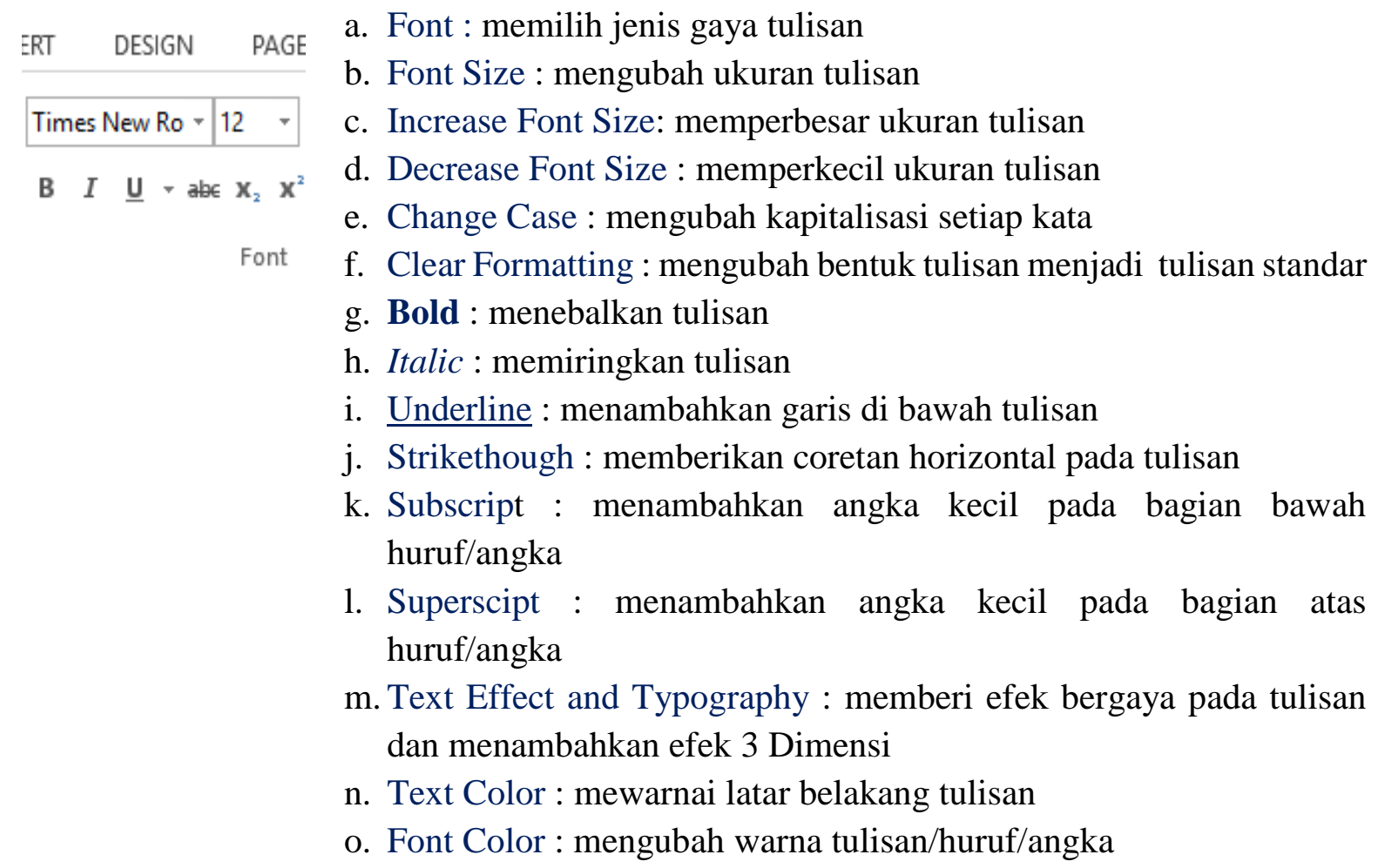

\section{Kelompok Paragraph}

Secara umum berfungsi untuk mengedit paragraf yang telah dibuat

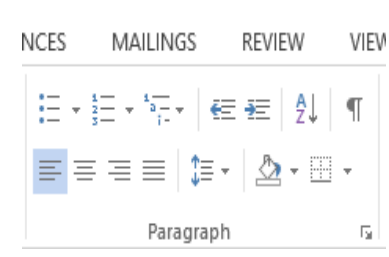

a. Bullets : memberikan tanda secara berurutan pada tulisan

b. Numbering : memberikan penomoran secara berurutan pada tulisan

c. Multilevel List : memberikan penomoran/tanda bertingkat pada tulisan

d. Decriese Indent : mendekatkan paragraf ke batas kertas

e. Increase Indent : menjauhkan paragraf dari batas kertas

f. Sort : mengurutkan tulisan yang dipilih sesuai abjad dari A ke Z atau $\mathrm{Z}$ ke $\mathrm{A}$

g. Show/Hide : menampilkan tanda paragraf dan simbol pemformatan tersembunyi lainnya

h. Align Left : meratakan paragraf ke batas kertas kiri

i. Align Center : meratakan paragraf ke batas kertas tengah

j. Align Right : meratakan paragraf ke batas kertas kanan

k. Justify : meratakan paragraf bagian kiri dan kanan

1. Line \& Paragraph Spacing : mengatur jarak antar baris dan paragraf

m. Shading : mengubah warna di belakang tulisan, tabel, atau paragraf

n. Border : menambahkan batas pada jendela penulisan/kertas 


\section{Kelompok Style}

Style : mengubah jenis gaya tulisan sesuai selera

\section{Kelompok Editing}

Secara umum berfungsi untuk menemukan, memilih dan mengganti kata, frase kata, tulisan, atau angka yang terdapat pada dokumen
Afin Find .
$\underset{4 \mathrm{ac}}{\mathrm{a}}$ Replace
Select -
Editing
a. Find : menemukan kata, frase kata, tulisan, atau angka yang terdapat pada dokumen
b. Replace : mengganti kata, frase kata, tulisan, atau angka yang satu dengan yang lain
c. Select : memilih tulisan atau objek gambar dalam dokumen

\subsection{Insert}

Menu Tab berikutnya pada Microsoft Word 2013 adalah INSERT. Menu INSERT ini terdiri dari beberapa kelompok sub tema antara lain (Gambar 6):

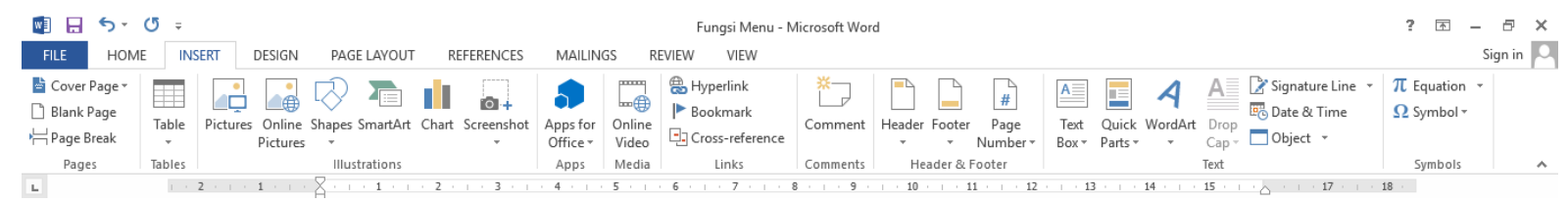

Gambar 6. Hasil screenshot tampilan dan kelompok tab menu INSERT

\section{Kelompok Pages}

FILE HOME a. Cover Page : membuat halaman sampul dokumen

늠 Cover Page
$\square$ Blank Page
Pages

b. Blank Page : menambahkan halaman Microsoft Word yang baru

c. Page Break : menghakhiri sesi halaman Microsoft Word yang sedang aktif dan berpindah ke halaman baru. Dengan menggunakan Page Break ini, ketika pada halaman sebelumnya ada penambahan tulisan, maka tidak akan membuat tulisan yang awal diketik turun ke baris berikutnya.

\section{Kelompok Tables}

Tables : membuat tabel pada halaman Microsoft Word dengan jumlah yang diinginkan

$$
\text { Table }
$$

\section{Kelompok Illustrations}

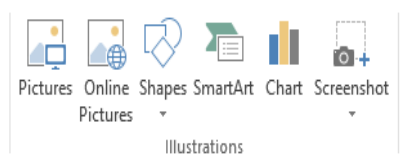

a. Picture : memasukkan file gambar dari laptop/komputer

b. Online Picture : memasukkan gambar dari beberapa sumber di internet

c. Shapes : menambahkan bentuk seperti segiempat, segitiga, bintang, lingkaran, dan lain sebagainya 
d. SmartArt : memasukkan diagram yang dapat memvisualkan dokumen

e. Chart : menambahkan bagan atau grafik untuk mempermudah pembacaan data

f. Screenshot : menambahkan tangkapan layar dari jendela yang sedang aktif

\section{Kelompok Apps}

Apps For Office : menambahkan program aplikasi ke dalam dokumen dengan bantuan akses internet

\section{Kelompok Media}

Video Online : mencari dan memasukkan file video yang diakses melalui internet ke dalam dokumen

\section{Kelompok Links}

\section{Hyperlink}

Bookmark

Cross-reference

Links a. Hyperlink : membuat link ke halaman website pada tulisan (kata, frase kata, kalimat, paragraf) yang dipilih

b. Bookmark : mempermudah pada saat membuka dokumen. Cara kerjanya adalah menambahkan bookmark pada teks yang telah diberikan hyperlink.

c. Cross-reference adalah hyperlink yang mana label/kategori dihasilkan secara otomatis.

\section{Kelompok Comments}

Comments : menambahkan catatan pada bagian tertentu dalam dokumen

Comment

\section{Kelompok Header \& Footer}

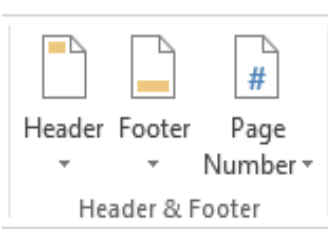

a. Header : menambahkan informasi seperti judul, penulis, kop surat, kop jurnal ilmiah dan lain-lain pada bagian atas halaman dokumen

b. Footer : menambahkan infrormasi pada bagian bawah halaman dokumen

c. Page Number : memberikan nomor halaman dokumen

\section{Kelompok Text}

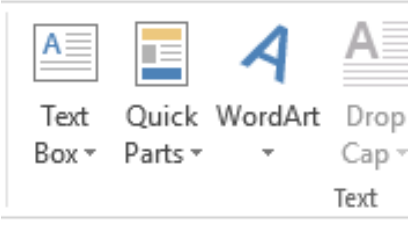

a.Text Box : menambahkan informasi penting ke dalam kotak tulisan

b. Quick Part : menambahkan tulisan yang sudah diatur agar memudahkan dalam mencari dokumen

c.WordArt : menambahkan teks dengan bentuk yang artistik 
d. Drop Cap : membuat sebuah huruf kapital besar pada awal paragraf

e. Signature Line : menambahkan baris tanda tangan

f. Date \& Time : menambahkan tanggal dan wakt secara cepat

g. Object : menambahkan objek yang disematkan.

\section{Kelompok Symbols}

$\pi$ Equation - a. Equation : menambahkan persamaan atau rumus matematika

$\Omega$ Symbol.

b. Symbols : menambahkan symbol-simbol yang tidak terdapat pada keyboard

\subsection{Design}

Menu Tab berikutnya pada Microsoft Word 2013 adalah DESIGN. Menu DESIGN ini terdiri dari beberapa kelompok sub tema antara lain (Gambar 7):

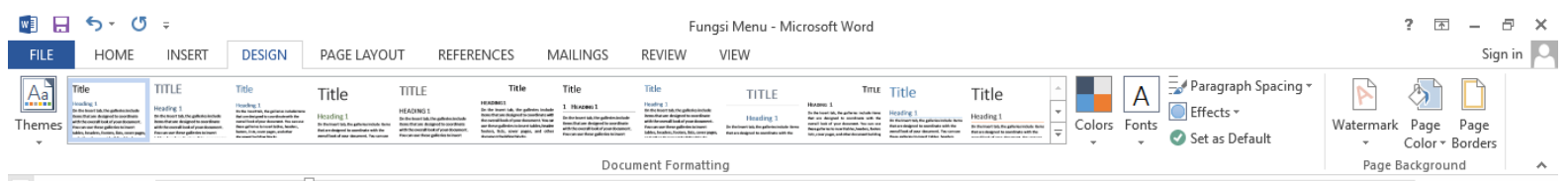

Gambar 7. Hasil screenshot tampilan dan kelompok tab menu DESIGN

\section{Kelompok Document Formating}

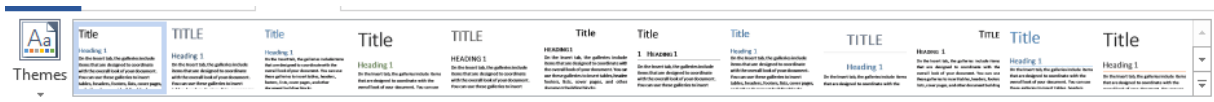

a. Themes : menambahkan tema pada dokumen

b. Colors : memilih warna tema pada dokumen

c. Fonts : memilih gaya huruf pada tema dokumen

d. Paragraph Spacing : mengubah jarak antar paragraf dengan cepat

e. Effect : memberikan perubahan efek pada objek terpilih

f. Set As Default : menjadikan gaya dokumen saat ini diterapkan pada dokumen lainnya

\section{Kelompok Page Background}

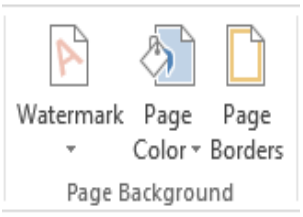
a. Watermark : menambahkan cap air pada bagian belakang teks
b. Page Color : memberikan warna pada halaman dokumen
c. Page Border : menambahkan bingkai pada sisi kertas

Page Background 


\subsection{Page layout}

Menu Tab berikutnya pada Microsoft Word 2013 adalah PAGE LAYOUT. Menu PAGE LAYOUT ini terdiri dari beberapa kelompok sub tema antara lain (Gambar 8):

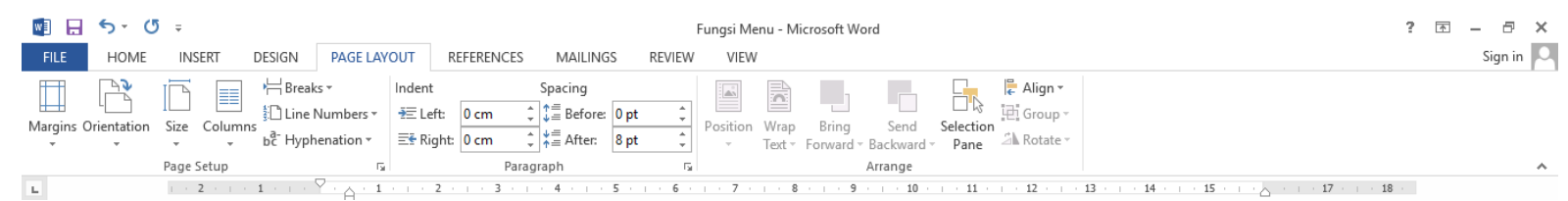

Gambar 8. Hasil screenshot tampilan dan kelompok tab menu DESIGN

\section{Kelompok Page Setup}

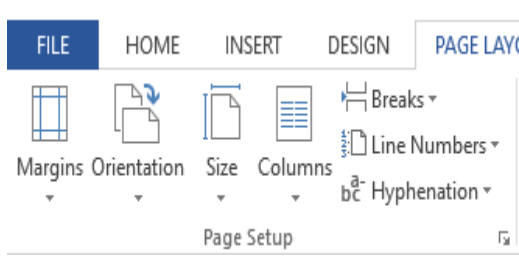

a. Margins : mengatur batas atas, bawah, kanan, dan kiri tulisan pada dokumen

b. Orientation : mengatur posisi halaman menjadi bentuk portrait atau landscape

c. Size : mengatur ukuran kertas yang digunakan

d. Columns : mengatur kolom pada dokumen

e. Breaks : mengatur kontinuitas halaman maupun kolom

f. Line Numbers : mengatur kontinuitas nomor baris teks

g. Hyphenation : memisahkan suku kata dengan tanda hubung secara otomatis

\section{Kelompok Paragraph}

\begin{tabular}{|c|c|c|c|c|}
\hline 'OUT & REFERENCES & MAILING & & REVIEW \\
\hline Indent & \multicolumn{4}{|c|}{ Spacing } \\
\hline 丙仼 Left: & $0 \mathrm{~cm}$ & \multirow{2}{*}{ 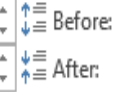 } & $0 \mathrm{pt}$ & $:$ \\
\hline$\equiv$ Right: & t: $0 \mathrm{~cm}$ & & $8 \mathrm{pt}$ & $:$ \\
\hline \multicolumn{4}{|c|}{ Paragraph } & $\sqrt{x}$ \\
\hline
\end{tabular}

a. Indent : mengatur batas kiri dan kanan tulisan

Left : mengatur batas kiri tulisan

Right : mengatur batas kanan tulisan

b. Spacing : mengatur jarak antar paragraf

Before : mengatur jarak tulisan dari paragraf sebelumnya

After : mengatur jarak tulisan dari paragraf sesudahnya

\section{Kelompok Arrange}

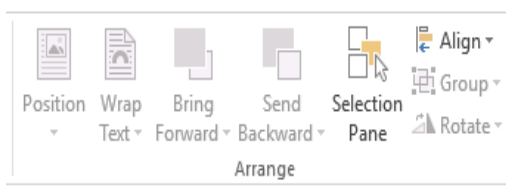

a. Position : mengatur posisi gambar terhadap tulisan

b. Wrap text : mengatur pelipatan tulisan sehingga ketika anda menyisipkan gambar maka dapat mengatur gambar ini sesuai dengan keinginan anda.

c. Bring to Front : meletakkan sisipan objek gambar yang dipilih ke posisi paling depan

d. Send to Back : meletakkan objek gambar yang dipilih ke posisi paling belakang

e. Selection pane : menampilkan panel navigasi objek

f. Align : meratakan objek yang dipilih

g. Group : menyatukan beberapa objek yang dipilih

h. Rotate : memutar suatu objek gambar yang kita masukan ke dalam dokumen 


\subsection{References}

Menu Tab berikutnya pada Microsoft Word 2013 adalah REFERENCES. Menu REFERENCES ini terdiri dari beberapa sub tema antara lain (Gambar 9):

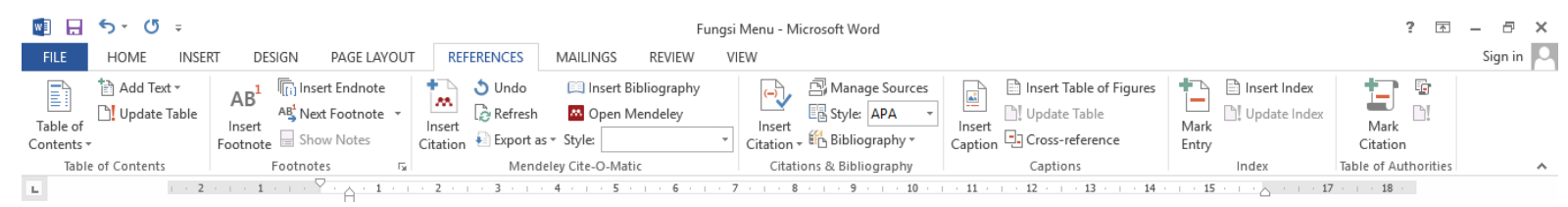

Gambar 9. Hasil screenshot tampilan dan kelompok tab menu REFERENCES

\section{Kelompok Table of Contents}

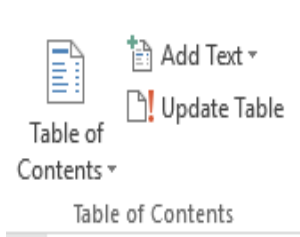

a. Table of Contens : mengatur daftar isi sesuai yang diinginkan

b. Add Text : mengelola paragraf yang dipilih dalam kaitannya sebagai entri dalam daftar isi yang sudah dibuat

c. Update Table : memperbarui daftar isi

\section{Kelompok Footnotes}

\begin{tabular}{|c|c|}
\hline$A R^{1} \sqrt{[\sqrt{[i j}} /$ nser & tau footer) \\
\hline $\mathrm{AB} \mathrm{Ne}$ & Endnote : menyisipkan catatan di akhir bab \\
\hline & emantau footnote dan endnote \\
\hline Fo & d. \\
\hline
\end{tabular}

\section{Kelompok Citation \& Bibliography}

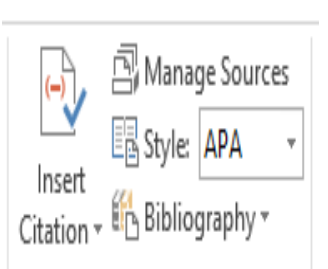

Citations \& Bibliography

a. Insert Citation : menyisipkan kutipan langsung pada daerah kursor aktif

b. Manage Sources : mengelola seluruh sumber kutipan yang mungkin sudah disisipkan di semua segmen file dokumen

c. Style : memilih bentuk bibliography yang diinginkan.

d. Bibliography : menyisipkan daftar pustaka ke dalam file dokumen aktif

\section{Kelompok Captions}

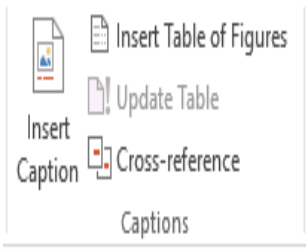

a. Insert Caption : membubuhkan keterangan seputar ilustrasi atau gambar yang sudah disisipkan

b. Insert Table of Figures : menyisipkan daftar isi gambar yang disisipkan ke dalam dokumen

c. Update Table : melakukan pembaruan terhadap daftar katalog gambar

d. Cross-reference : menyisipkan referensi silang 


\section{Kelompok Index}

\begin{tabular}{ll}
\hline Mark & Gl Insert Index \\
Entry & \\
& Index \\
\hline
\end{tabular}

a. Mark Entry : menandai masukan baru dalam dokumen

b. Insert index : menyisipkan daftar kata (indeks) ke dalam dokumen

c. Update Index : memperbarui daftar indeks terkini.s

\section{Kelompok Table of Authorities}

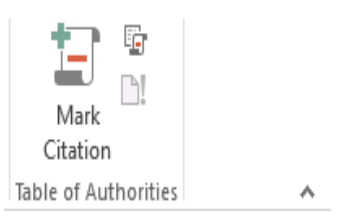

a. Mark Citation : nenambahkan tulisan yang telah dipilih untuk dimasukkan kedalam table of authorities
b. Insert Table of Authorities : menyisipkan table of authorities pada dokumen

\subsection{Mailings}

Menu Tab berikutnya pada Microsoft Word 2013 adalah MAILINGS. Menu REFERENCES ini terdiri dari beberapa kelompok sub tema antara lain (Gambar 10):

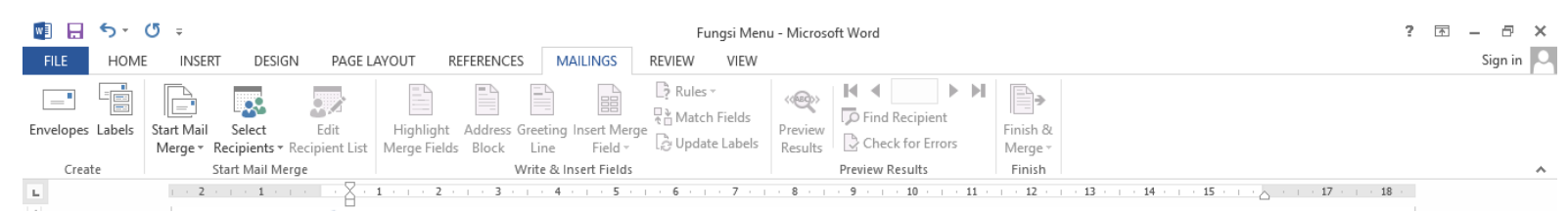

Gambar 10. Hasil screenshot tampilan dan kelompok tab menu MAILINGS

\section{Kelompok Create}

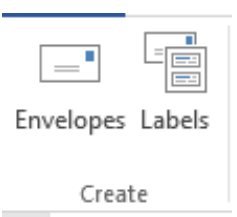

a. Envelopes : membuat dan mencetak tulisan mengenai pengirim dan penerima surat pada amplop

b. Labels : membuat dan mencetak tulisan pada label sesuai dengan bentuk dan ukuran label yang akan diberi tulisan

\section{Kelompok Start Mail Merge}

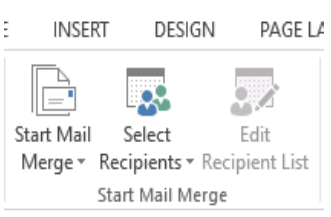

a. Start Mail Merge : membuat surat yang dapat dikelola untuk banyak orang sekaligus

b. Select Recipients : membuat dan mengelola daftar penerima surat

c. Edit Recipient List : mengadakan perubahan pada daftar penerima surat

\section{Kelompok Write \& Insert Fields}

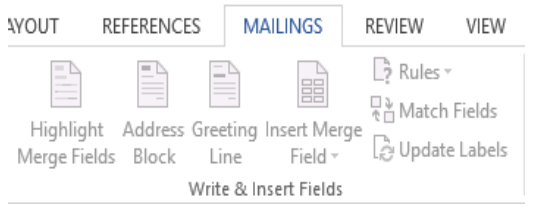

a. Highlight Merge Fields : mengetahui dan mengubah adanya informasi yang salah terkait surat yang sedang buat

b. Address Block : memasukkan alamat tujuan pada surat yang dibuat 
c. Greeting Line : menambah nama sapaan dari penerima surat

d. Insert Merge Field : memasukkan informasi tambahan tentang penerima surat

e. Rules : menambah dan menggabungkan keputusan tindakan pada surat dengan memanfaatkan penyimpanan awan/cloud yang tersedia

f. Match Fields : memeriksa dan mencocokkan identitas penerima agar tidak terdapat penerima ganda

g. Update Labels : memperbarui label surat sesuai dengan keadaan terkini

\section{Kelompok Preview Results}

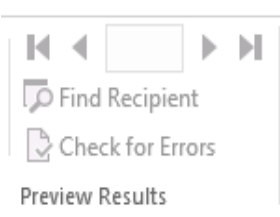

Preview Results a. Preview Results : melihat surat beserta daftar penerima yang telah dibuat

b. Find Recipient : mencari identitas penerima surat sesuai dengan daftar penerima surat yang telah dibuat

c. Auto Check for Errors : memeriksa secara otomatis apakah ada kesalahan dalam surat yang telah dibuat

\section{Kelompok Finish}

Finish Merge : melakukan tindakan lanjutan setelah surat yang dibuat sudah lengkap dan selesai dikerjakan

\subsection{Review}

Menu Tab berikutnya pada Microsoft Word 2013 adalah REVIEW. Menu REVIEW ini terdiri dari beberapa kelompok sub menu antara lain (Gambar 11):

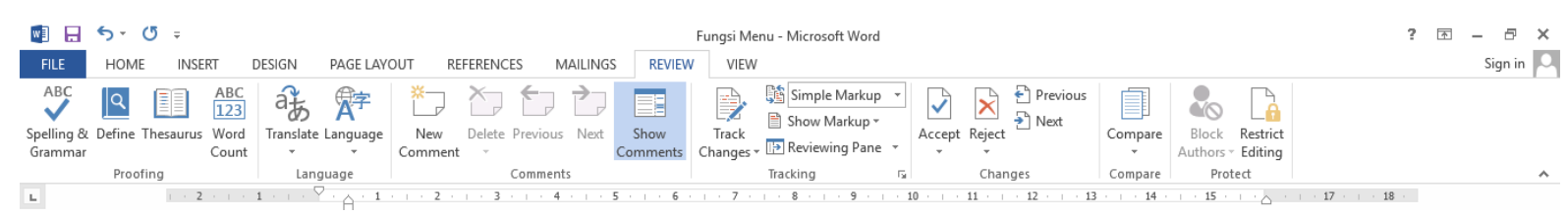

Gambar 11. Hasil screenshot tampilan dan kelompok tab menu REVIEW

\section{Kelompok Proofing}

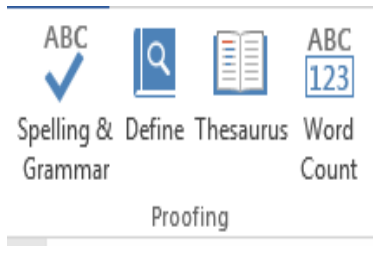

a. Spelling \& Grammar : mengecek ejaan tulisan yang benar sesuai dalam ejaan dan tata bahasa termasuk penggunaan tanda baca yang baik dan benar sesuai dengan EYD

b. Define : memastikan makna suatu kata

c. Thesaurus : menampilkan alternatif kata dari teks yang diketikkan di dalam sel

d. Word Count : menghitung jumlah halaman, kata, karakter tanpa spasi, karakter dengan spasi, paragraf dan garis dari sebuah dokumen 


\section{Kelompok Languange}

ât Aि

Translate Language

Language

a. Translate : menerjemahkan tulisan dari suatu bahasa ke bahasa yang lain

b. Language : mengatur bahasa tulisan yang dapat saling diterjemahkan

\section{Kelompok Comment}

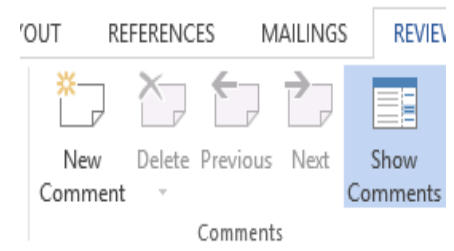

a. New Comment : menambahkan komentar baru pada tulisan, kata, frase kata, kalimat, atau paragraf

b. Delete : menghapus komentar yang sudah dibuat

c. Previous : melihat komentar sebelumnya

d. Next : melihat komentar sesudahnya

e. Show Comment : menampilkan semua komentar yang sudah dibuat

\section{Kelompok Tracking

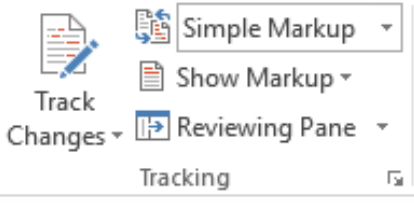

a. Track Changes : melacak perubahan yang dibuat pada dokumen ini. Hal ini sangat berguna jika dokumen hampir selesai dan kita bekerja dengan orang lain untuk melakukan revisi atau memberi umpan balik

b. Simple Markup : memilih bagaimana kita ingin melihat perubahan di dalam dokumen

c. Show Markup : memilih jenis markup yang akan ditampilkan di dalam dokumen

d. Reviewing Pane : menampilkan semua perubahan pada dokumen kita dalam daftar

\section{Kelompok Changes}

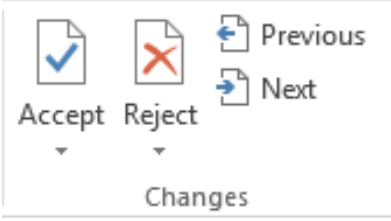

a. Accept : klik untuk opsi opsional tambahan, seperti menerima semua perubahan sekaligus

b. Reject : klik untuk opsi opsional tambahan, seperti menolak semua perubahan sekaligus

c. Previous : berpindah ke perubahan yang dilacak sebelumnya

d. Next : berpindah ke perubahan yang dilacak berikutnya

\section{Kelompok Compare}

Berfungsi untuk membandingkan dua dokumen untuk melihat perbedaan di antara Compare keduanya

Compare

\section{Kelompok Protect}

a. Block Authors : -

b. Restrict Editing : membatasi berapa orang dalam mengedit dan memformat dokumen 


\subsection{View}

Menu Tab berikutnya pada Microsoft Word 2013 adalah VIEW. Menu VIEW ini terdiri dari beberapa kelompok sub menu antara lain (Gambar 12):

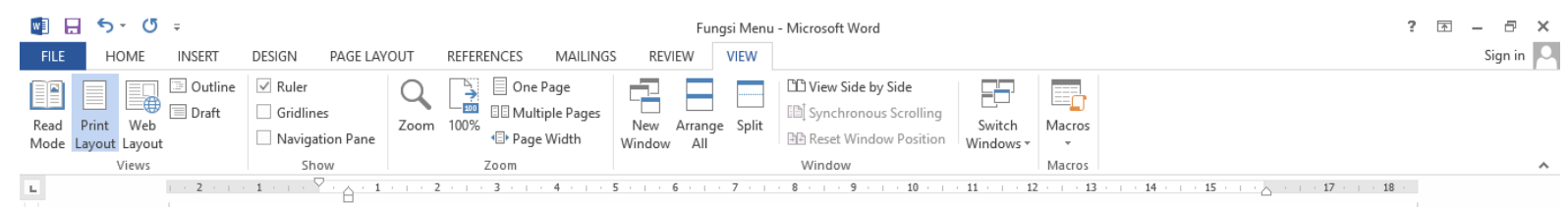

Gambar 12. Hasil screenshot tampilan dan kelompok tab menu VIEW

\section{Kelompok Views}

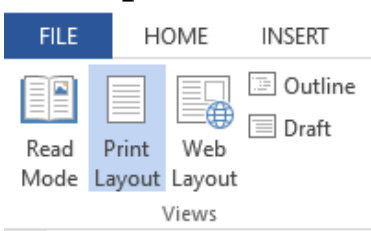

a. Read Mode : merubah tampilan halaman dokumen menjadi bentuk yang mudah dan nyaman untuk dibaca

b. Print Layout : memeriksa bagaimana dokumen akan terkunci saat dicetak

c. Web Layout : melihat tampilan dokumen sebagai halaman web

d. Outline : melihat tampilan dokumen sebagai tampilan outline

e. Draft : melihat tampilan dokumen sebagai tampilan draft

\section{Kelompok Show}

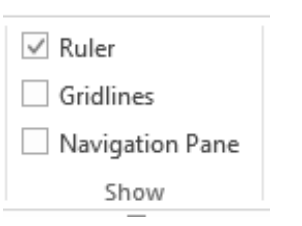

Kelompok Zoom

OUT REFERENCES MALINGS

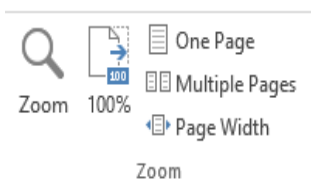

a. Ruler : menampilkan/menyembunyikan garis

b. Gridlines : menampilkan/menyembunyikan garis bantu lembar kerja

c. Navigation Pane : menavigasi dokumen ke dalam heading, page dan result

a. Zoom : memperbesar atau memperkecil tampilan dokumen sesuai keinginan

b. $100 \%$ : mengembalikan tampilan dokumen ke ukuran $100 \%$

c. One Page : menampilkan 1 halaman dokumen

d. Multiple Pages : menampilkan banyak halaman dokumen

e. Page With : menampilkan halaman dokumen sesuai ukuran computer/laptop

\section{Kelompok Window}

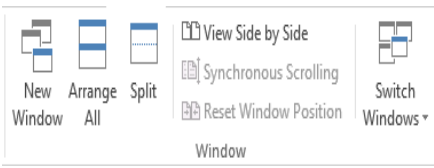

a. New Window : membuka jendela dokumen kedua sehingga kita dapat bekerja di tempat yang berbeda pada waktu bersamaan

b. Arrange All : menumpuk jendela yang terbuka sehingga kita bisa melihat semuanya secara bersamaan

c. Split : melihat dua bagian dokumen pada saat bersamaan 
d. View side by Side : membolak-balikan dokumen dan melihatnya secara berdampingan sehingga kita dapat membandingkannya dengan lebih mudah

e. Synchronous Scrolling : membandingkan dokumen baris demi baris

f. Reset Window Position : menempatkan dokumen yang kita bandingkan menjadi berdampingan

g. Switch Windows : memindahkan dari satu jendela aktif ke kendela aktif lainnya

\section{Kelompok Macros}

berfungsi untuk memperlihatkan Macros pada halaman tulisan Microsoft Word

\section{Kesimpulan}

Tab menu yang terdapat dalam Microsoft Word 2013 terdiri dari Home, Insert, Design, Page Layout, References, Mailings, Review, dan View. Masing-masing tab menu tersebut berfungsi untuk memaksimalkan fungsi dari aplikasi Microsoft Word 2013. Dengan demikian, akan dapat membantu tugas-tugas dalam bidang akademik dan perkantoran.

\section{Daftar Pustaka}

1. Adi, A. P., 2017. The Best Tips \& Trick Ms Office : Powerpoint. Jakarta : Penerbit PT Elex Meia Komputindo.

2. Hasyim M. 2009. Buku Pintar Microsoft Office. Jakarta : Kriya Pustaka.

3. Hatoko, Alfa. 2016. Top 125 Penerapan MS Office 2013. Jakarta : Penerbit PT Elex Meia Komputindo. 